\title{
Modeling and Simulation of a Vertical Wind Power Plant in Dymola/Modelica
}

\author{
Joel Petersson* \\ Joel.pettersson@gmail.com \\ Hubertus Tummescheit ${ }^{\dagger}$ \\ hubertus.tummescheit@modelon.com \\ * Lund University \\ Sölvegatan 18 \\ SE-22100, Lund, Sweden \\ www.lth.se
}

\author{
Pär Isaksson* \\ Par.Isaksson.lth@gmail.com \\ Johan Ylikiiskilä ${ }^{\dagger}$ \\ johan.ylikiiskila@modelon.com \\ ${ }^{\dagger}$ Modelon AB \\ Ideon Science Park \\ SE-22370, Lund, Sweden \\ www.modelon.com
}

\begin{abstract}
A small wind power plant connected to the grid has been modeled in Modelica/Dymola and controlled using external controllers written in $\mathrm{C}++$. The small wind power plant consists of three wind power units, with a nominal power of $3 \mathrm{~kW}$, and one grid connection interconnected with an internal DC-grid. All the controls needed for controlling and optimizing the operation of the individual parts in the plant were developed and implemented. Apart from this a managing control for the entire plant were developed and implemented.

The control was implemented using an external static library interconnected with Dymola. the External Object approach for implementing objects in Modelica was also tested. The optimization algorithms developed for the wind turbine was done in a way so that no measurements of the wind speed are needed. The controls were developed so that they can achieve a number of different tasks such as Reactive Power Compensation and Island Control.

Models were implemented in Modelica using Dymola as tool. In order to model the power electronics involved in the system the Electric Power library (EPL) has been utilized. Models for the wind turbine were developed and tested.

The models were in the end tested and evaluated by running a number of different simulations. The Different test cases consists of optimizing the power output, controlling the power output to a desired level and island operation, that is to power up a small grid on its own.

Keywords: wind power, power electronics, control, optimization, vertical wind power, Electrical Power library
\end{abstract}

\section{Nomenclature}

\section{$P$}

$C_{p}$

$T_{\omega}$

$\beta$

$\lambda$

$\lambda_{i}$

$\omega_{T}$

$\rho$

$c_{1-6}$

\section{A}

\section{Introduction}

Wind power is at the moment in a globally expansive phase with different kinds of technical solutions and suppliers. In most solutions power electronics is incorporated to smaller or larger extent. Most wind power plants currently operate with a horizontal axis turbine, however vertical axes turbines is an interesting future 


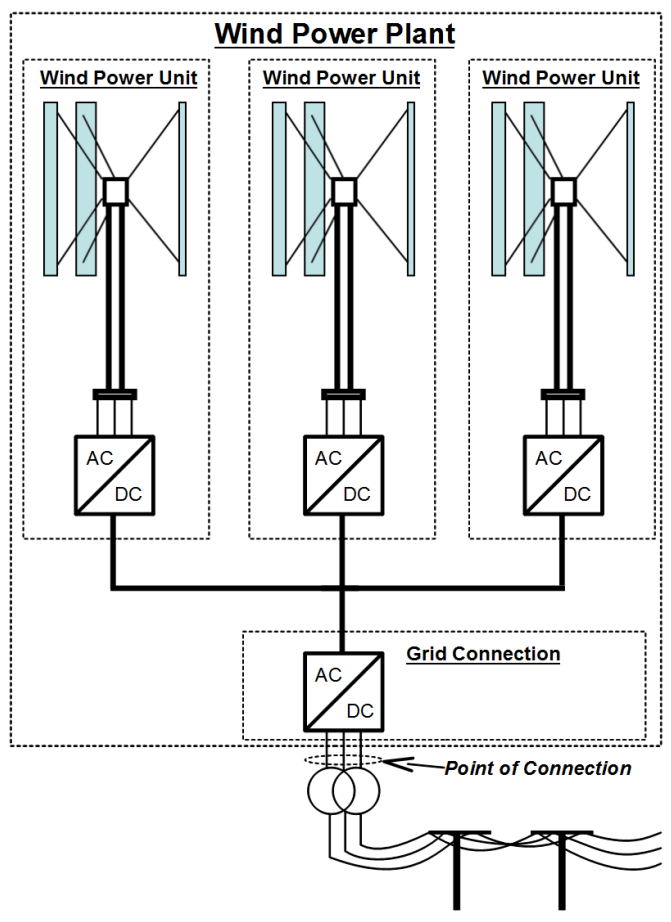

Figure 1: Schematic picture of how the wind power system is set up.

alternative. Vertical plants have been erected and are now being tested in Sweden.

The advantages of using a vertical axes turbine are a simple and robust construction with a minimal amount of moving parts, which allows for a cost efficient wind power plant with an aspect both to investment, operation and maintenance. Other pros are independence of wind direction, less sensitivity to turbulence, simple blade profiles and lower noise levels.

The objective of this project was to model and control a small wind power plant consisting of one or several wind power units and one grid connection interconnected with an internal DC-grid. The configuration of investigated can be seen in figure 1 . This article will mainly focus on the case with one single wind power unit connected to the grid through back to back full inverters ${ }^{1}$. The models and controls developed will be tested by running different test cases. They will also be evaluated according grid codes, see [1] \& [2].

\section{Modeling}

The system to be modeled consists, as depicted in figure 2 , of a wind turbine connected through a break to

\footnotetext{
${ }^{1}$ Back to back full inverters consists of two inverters coupled by a DC-grid, i.e. the DC-connection of the generator inverter is coupled to the DC-connection of the grid inverter.
}

a generator. The power voltage output from the generator is rectified by an inverter connected to a DC-grid which is then connected via another inverter to a threephase grid. The reason to why an internal DC-grid is utilized is mainly to decouple the rotational speed of the wind power units from the grid frequency, the DCgrid also acts as both filter and buffer.

\subsection{Wind Turbine}

Wind turbine power generations depend on the interactions between the wind and the rotor. The power extracted from the wind by the rotor can be described as the kinetic energy of the wind times an efficiency coefficient. The efficiency coefficient is varying with the pitch angle of the blades and tip speed ratio. The tip speed ratio is the wind speed relative the speed of the tip of the turbine's blades. The mechanical power $P$ in a vertical wind power unit can be described by equation 1 . The efficiency coefficient, $C_{p}$, can be described according to equation 2 , as proposed in [3] and [4].

$$
\begin{gathered}
P=\frac{1}{2} \cdot \rho \cdot A \cdot v^{3} \cdot C_{p} \\
C_{p}(\lambda, \beta)=c_{1} \cdot\left(\frac{c_{2}}{\lambda_{i}}-c_{3} \cdot \beta-c_{4}\right) \cdot e^{\frac{-c_{5}}{\lambda_{i}}}+c_{6} \cdot \lambda \\
\frac{1}{\lambda_{i}}=\frac{1}{\lambda+0.08 \cdot \beta}-\frac{0.035}{\beta^{3}+1} \\
\lambda=\frac{\omega_{T} \cdot R}{v}
\end{gathered}
$$

The area swept by a vertical wind power turbine is simply expressed as the rotor diameter times the rotor length. The efficiency coefficient, $C_{p}$, can be calculated according to equation 2 to 4 . A typical $C_{p^{-}}$ curve for different pitch angles ${ }^{2}$ can be seen in figure 3 . The mechanical torque $T_{\omega}$ can be obtained by dividing the power absorbed, $P$, with the rotational speed of the turbine, $\omega_{T}$. A component modeling the effect of tower shadow was also implemented according to [5]. The tower shadowing effect occurs when a rotor blade passes behind the tower, this since it is then shadowed from the wind by the tower. This was modeled by subtracting a torque component each time a rotor blade passes behind the tower.

$$
T_{\omega}=\frac{P}{\omega_{T}}
$$

\footnotetext{
${ }^{2}$ The pitch angle is the angle at which the rotor's blade surface contacts the wind.
} 


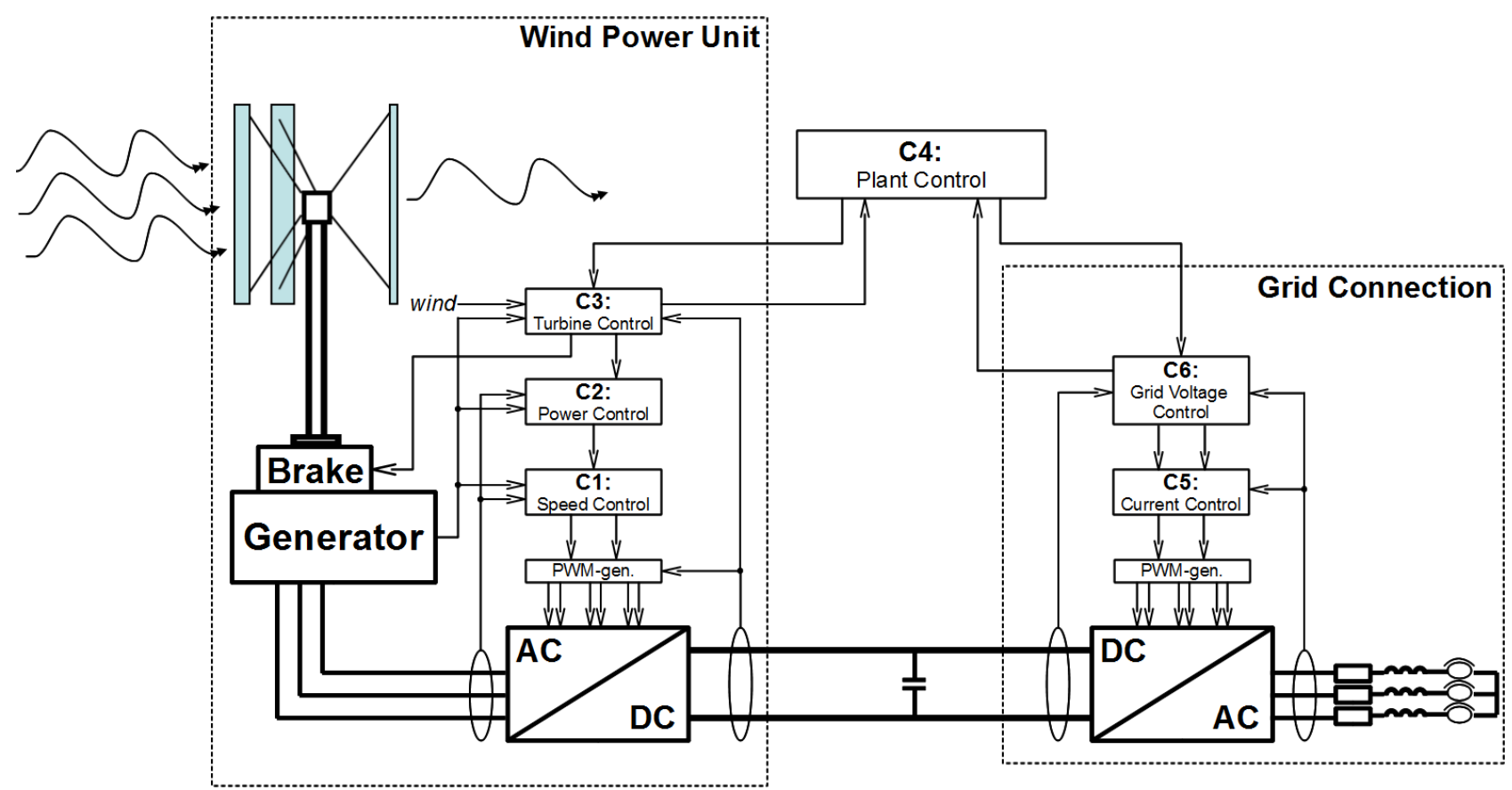

Figure 2: Overview of control structure and configuration of the wind power plant.

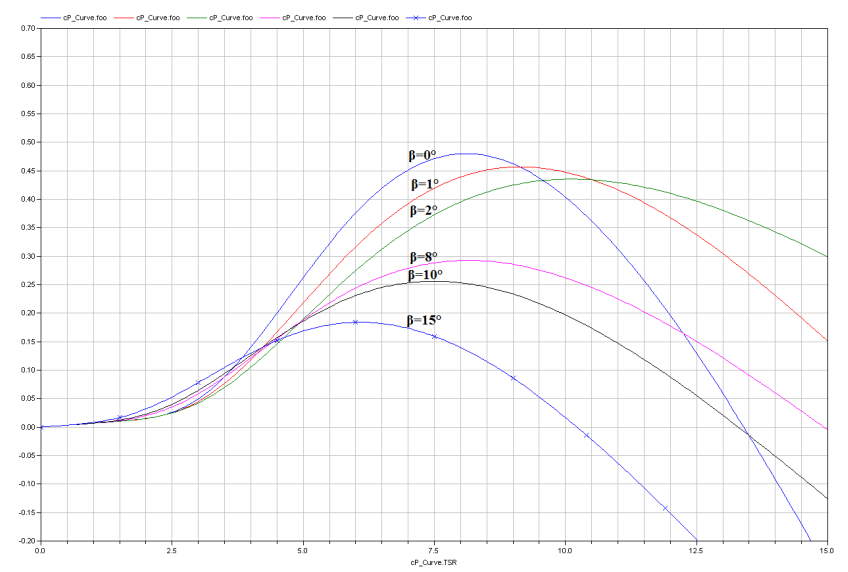

Figure 3: Typical characteristic of a $C_{p}$-curve at different pitch-angles, $\beta$

Apart from modeling the wind turbine as an energy producing unit modeling of the actual mechanical and electrical properties also needs to be done in order to get a good overall model. The wind turbine was modeled to be directly coupled to a shaft and via a brake to the permanent magnet generator. The shaft was modeled as inertia, containing both the rotor's inertia and the actual shaft's inertia, coupled via a model of coulomb friction in bearings, in order to simulate losses in the shaft, to the brake. For modeling of the inertia, bearing friction and brake components from Modelica's standard library was used.

\subsection{Wind Model}

The produced power of a wind turbine is tightly linked to the current wind speed. The wind changes both during the day and the seasons. In order capture these changes and to simulate the real wind conditions, a wind model consisting of three components is used in this project. The three components are:

- A base component, $v_{\text {base }}$

- A gust component, $v_{\text {gust }}$

- A noise component, $v_{\text {noise }}$

The three components are summarized to $\mathrm{v}=v_{\text {base }}$ $+v_{\text {gust }}+v_{\text {noise }}$. The base component is always present, it may be constant, a ramp signal or have any other form. The gust component appears randomly during time and the noise component is modeled as white noise.

\subsection{Power Electronics}

The system is designed using back to back full inverters. This means that the modeling of the power electronics becomes essential for the complete model. This since the power electronics is used for controlling both the individual wind power units and grid connection. The Electric Power Library was chosen to be the main tool used for modeling the power electronics and generators since it is well suited for the task. 


\subsubsection{The Electric Power Library}

The Electric Power library is a Modelica library used for modeling of power electronics and can be used in both steady state and transient mode for the simulations and initializations. The Electric Power library provides components for modeling $\mathrm{AC}$ three phase system, AC one phase systems and DC system. The AC three phase systems can be represented in the abc, dqo- and dq-frame. Especially modeling in the dqo/dq- reference frame provides relatively quick simulations, compared to simulations in the abc-reference frame. This since a symmetrical three phase voltage or current is represented by constants in the dq0reference frame. The Electric Power library was originally written by H.J. Wiesmann and is currently owned and sold by Modelon AB.

The Electric Power Library supports modeling in the dq0-reference frame. The dq0-reference frame not only simplifies analysis of the system but also increases the simulation speed.

The main components used from the Electric Power library were models for the inverters, a model for a Permanent Magnetized Synchronous Machine, PMSM, DC-link model and models for transmission lines. The rotor connection of the PMSM model is compatible with the Modelica standard library.

\section{Control Design}

In order to control the wind power plant different controls are needed. The controls are developed to achieve a number of different operation modes that are needed in order to achieve the grid codes. The overall control structure developed can be seen in figure 2. A short description of the different controllers follows below, for more detailed descriptions see [6].

\subsection{Wind Power Unit Control}

The control needed to control the wind power unit has been divided into three controllers the Turbine Control, the Power Controller and the Speed Controller.

\subsubsection{Turbine Control}

The Turbine Control's task is to manage the wind power unit, which is to decide when the unit should start and stop as well as to give instructions as to which mode the unit currently should be working in. The Turbine Control should communicate with both the
Plant Control and the Power Controller. The communication should be kept to a minimum and no actual control should be done by the Turbine Control and Plant Control. The controller's main task is to make decisions about when the unit could be in operation and provide information about the unit's current capacity to the Plant Control. In order to do this the Turbine Control needs information about the current wind speed as well as orders from the Plant Control. Apart from this the control also needs information about how fast the rotor is spinning. This to avoid using the brake at high speeds and instead do a soft deceleration using the generator.

\subsubsection{Power Controller}

In order to control the power output from the wind power unit the Power Controller was developed. By controlling the power output from the wind power unit a number of different control modes can be achieved. The Power Controller is designed in two different sections.

The first part's task is to set an appropriate power reference for the second part. This power reference mainly depends on what control mode that is desired. For example when ordered to control the DC-voltage level the Power Controller receives a power offset. The power offset received is the current power input needed from the wind power unit in order for the total power input to be equal to the power output, thus keeping the DC-voltage level inert. The Power Controller then calculates the power reference as a deviation from the power offset in order to control the DCvoltage level.

The second part's task is to control the power output from the wind power unit to the reference value. This is done by adjusting the rotational speed of the turbine. As long as the wind speed is high enough for achieving the desired power the task is quite trivial and easily achieved by a PI-controller. However when the wind speed is too low and the desired power cannot be reached the controller should do as good as possible. In this case the controller should maximize the power output from the plant. The algorithm used to optimize the rotational speed was based on the sensorless maximum power point racking algorithm proposed in [7].

A flow chart over the general operation of the Power Controller can be seen in figure 4. The general idea with the control is to determine whether the current operation point is to the left or right of the optimal point, and depending on this take different actions.

The control algorithm starts by setting initial con- 


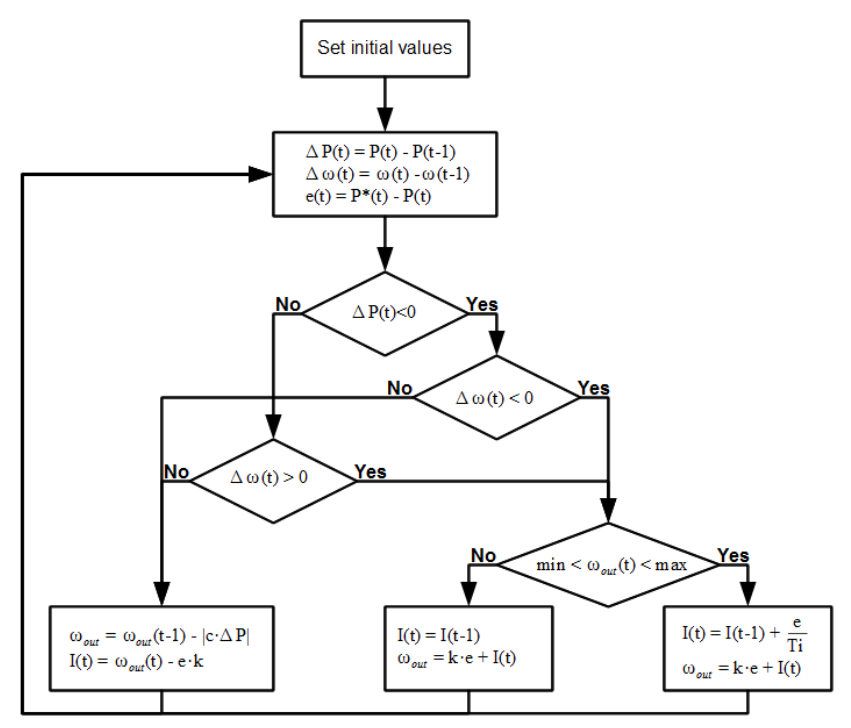

Figure 4: Flow chart for the power control algorithm

dition and reads new measurements. It then tries to decide whether the current operation point is to the left or right of the optimal by comparing the change in power output and the change in rotational speed. If the current operating point is considered to be on the left side of the optimal point the control output is calculated by a PI-controller with a simple antiwindup. If it is considered to be on the right side of the optimal point the control output is calculated as $\omega_{\text {out }}(t)=\omega_{\text {out }}(t-1)-|c \cdot \Delta P|$ where $c$ is a control constant and $\Delta P$ is the change in power. Also the integral for the PI-controller is updated in order to achieve a bumpless transfer between the two controls. That is when a control switch is made the output from the "new" control is equal to that of the "old".

\subsubsection{Speed Controller}

The speed controller consists of a series of cascaded PI- and PIE-controllers. The PIE-controller is a PIcontrol which is compensated by feed-forwarding the back electromagnetic force from the generator. The control parameters are calculated based on the generator parameters. The outer controller is a PI-controller controlling the rotational speed of the turbine by generating a torque reference. The requested torque can be achieved in many different ways, according to equation 6, where $T, p p, \psi_{m}, L_{s d}$ and $L_{s q}$ are generator parameters and $i_{s d}$ and $i_{s q}$ are currents in the respective axes. In this project a method was chosen were the direct current, $i_{s d}$, is set to zero, which generates the current references in equation 7 .

$$
\frac{T}{p p}=\psi_{m} i_{s q}+\left(L_{s d}-L_{s q}\right) i_{s d} i_{s q}
$$

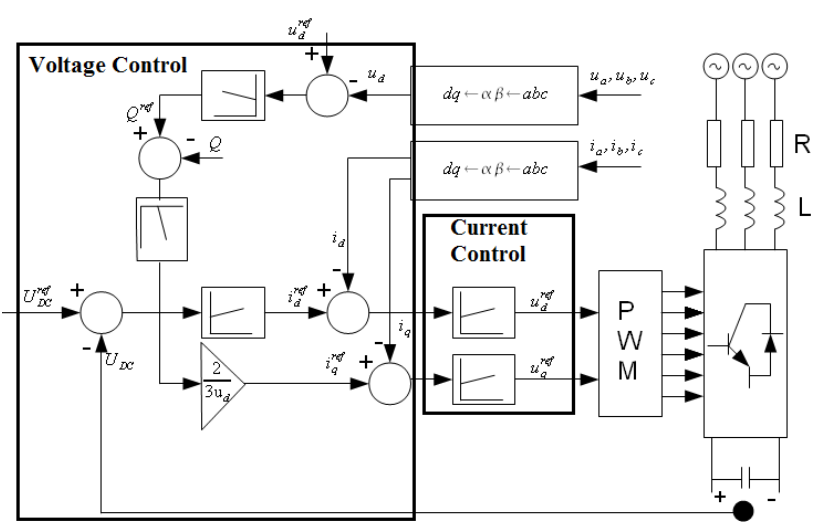

Figure 5: Schematic picture of the control structure used for controlling the grid connection.

$$
\Rightarrow\left\{\begin{array}{l}
i_{s d}^{r e f}=0 \\
i_{s q}^{r e f}=\frac{T^{r e f}}{\psi_{m} \cdot p p}
\end{array}\right.
$$

The two inner PIE-controllers control the currents of the PMSM which are designed according to [8].

\subsection{Grid Connection Control}

The control needed for the grid connection has been divided into two controllers the Voltage Control and the Current Control.

\subsubsection{Voltage Control}

The Voltage Control's task is to control the active and reactive power flow at the point of connection. This can be done in different ways depending on which control goal is desired. For example Swedish wind power plants are supposed to deliver zero reactive power. However in a small system the reactive power flow can be controlled so that the output voltage level to the grid is kept constant, independent of the active power output. Another possible control mode is Island operation in which the plant powers up the grid and controls the grid's voltage and frequency.

\subsubsection{Current Control}

The current controllers are implemented as two parallel PI-controllers controlling the direct and quadrature currents. The current references are received from the voltage control. The currents are controlled by outputting a reference voltage to the transistor control, modulator. The modulator uses the requested voltages 
in order to control the transistor by generating by generating switch signals for each of the individual inverters.

\subsection{Wind Power Plant Control}

The Plant Control's task is to manage the wind power plant. Most of its operation consists of setting the control modes of the grid connection and wind power units to achieve a specific control goal. The control could be done very simplistic, very advanced or anyway in between. The implementation done here was kept quite simplistic with some intelligence, for example loss compensation and ability to choose the number of plants that should be in operation and is covered in [6].

\section{Implementation}

\subsection{Wind Power Unit}

Most of the implementation was done using Modelica's standard library and Modelon's Electric Power library, however some models for the wind turbine was developed as well as a wind model.

An overview of the Modelica model over a wind power unit can be seen in figure 6 , to the right is the top view, with inverter and controllers, and to the left is the contents of the actual unit, with generator, shaft and turbine model. The unit model consists of a model of the turbine connected to a shaft, modeled as an inertia and a bearing friction. The shaft is connected via a brake to the permanent magnet synchronous generator, PMSG, the electrical output from the PMSG is connected to an inverter which performs an AC to DC conversion. Additionally a wind model was developed in order to model the wind in a realistic way. The inverter is controlled by the control-blocks on top of it, and by performing the AC/DC conversion the inverter controls the generator. As can be seen most models incorporated in the wind power unit model are from either Modelica's standard library or Modelon's Electric Power library. The models implemented in this project are the turbine model, wind model, the controllers and an interface between the control and the inverter. The model of the turbine was implemented using equations 1 to 5 .

\subsection{Grid Connection}

The grid connection is modeled using components from the Electric Power library. The grid model con-

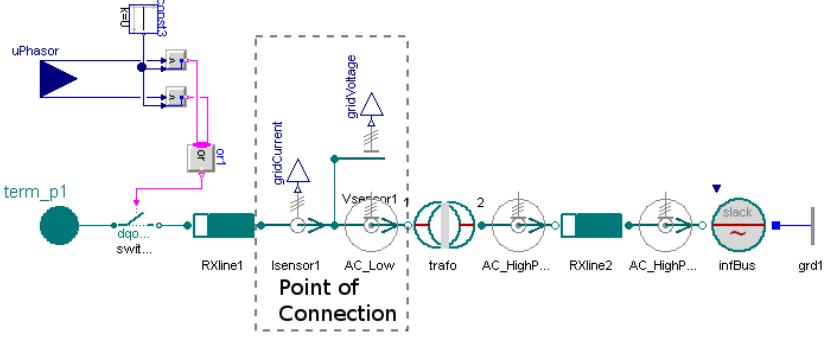

Figure 7: Screenshot of a strong grid model implemented in Dymola.

sist of a transmission line to the point of connection. After the point of connection follows a transformer and another, longer, transmission line. The model shown in figure 7 is depicting a model of a strong grid. In order to model a strong grid an optimal voltage source is connected to the long transmission line. The switch implemented before the first transmission line is necessary since the average inverter model used is based on a voltage source which means that when in passive mode it acts as a ground connection.

\subsection{Control}

There are two possibilities when trying to implement $\mathrm{C} / \mathrm{C}++$ objects into Dymola/Modelica. The first is using an External Static Library and the second is using the External Object function in Modelica. Both methods have their pros and cons. The External Static Library is disconnected from the modeling tool to a greater extent while the External Object is more interconnected with Modelica. In the end the decision was made to mainly use the External Static Library for implementation of the control structure. This was due to two different reasons.

1. The goal was to be able to run the exact same code both in simulations and on the actual plant and for this reason it was desirable to separate the control code and the models as much as possible.

2. The External Object currently only supports code in FORTRAN 77 and C [9], while the static external library supports both $\mathrm{C}$ and $\mathrm{C}++$.

However the External Object was also investigated and tested. The control blocks implemented in Dymola can be seen in figure 6 and 8 while a detailed description is covered in [6].

\subsection{Wind Power Plant}

Two different Modelica models were developed, however the only difference between the two is the num- 


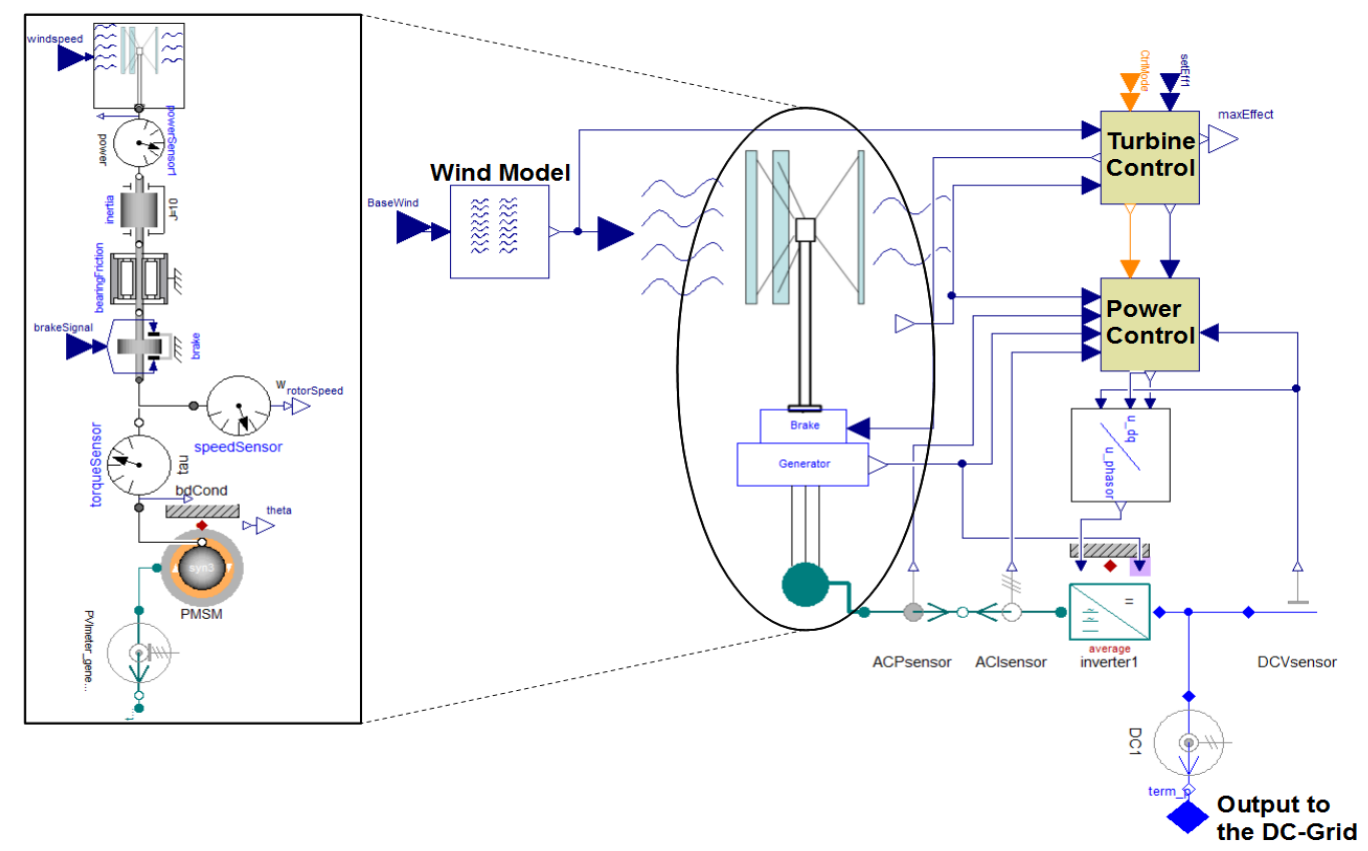

Figure 6: Screenshot of the wind power unit model in Dymola.

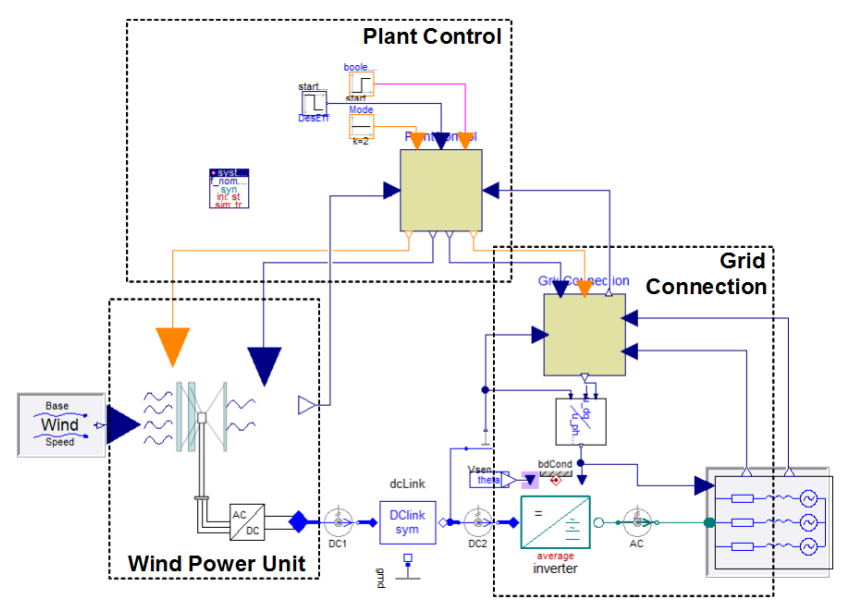

Figure 8: Screenshot of a wind power plant model using one wind power unit in Dymola.

ber of wind power units that is connected to the DCgrid. The models were constructed by connecting one or more wind power unit models to a model of a DClink, the DC-link was then connected to the grid connection model. In reality the wind acting on the different wind power units is not identical. The wind model was moved to the wind power unit model to reflect this fact.

\section{Results}

\subsection{Optimizing Operation Point}

This test is designed for evaluating performance of the optimizing algorithms of the Power Controller. The task in this case is to maximize the power output from the unit when the wind speed is not high enough to achieve the requested power output. The unit starts at standstill.

The results from the simulation are shown in figure 9. As can be seen the wind speed starts at $8 \mathrm{~m} / \mathrm{s}$ and after $200 \mathrm{~s}$ it increases to $11 \mathrm{~m} / \mathrm{s}$ over $100 \mathrm{~s}$. When observing the power output from the unit it can be noticed that the output is almost zero until the rotational speed reference has been reached, this since the generator is not applying any negative torque. After this the power output is approximately $1 \mathrm{~kW}$, and when observing the $C_{p}$-value in figure 9 it can be seen that it is very close to its maximum, which for this test was $\sim 0.26$. When the wind speed is increased the Power Controller reacts and adjusts the rotational speed of the rotor, and after some time the $C_{p}$-value has been returned to its maximum. It takes some time for the algorithm to recover after the increase in wind speed, however the value is maintained in the proximity of the maximum during this time. The wind gusts are reflected both in the output power and the $C_{p}$-value. The main reason to why the effect is so visible in the output power is that the wind power unit which was simulated is quite small, a bigger rotor, with higher in- 

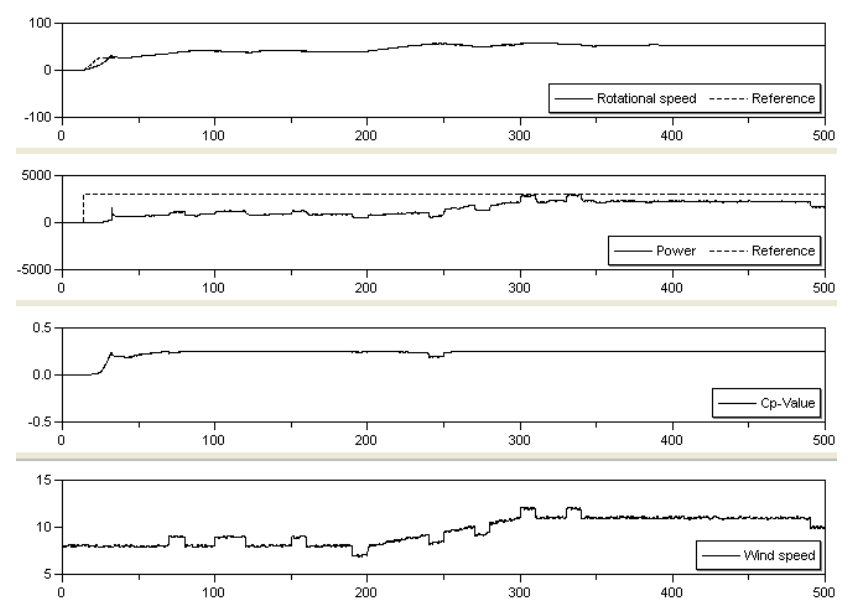

Figure 9: Simulation results, plotted from top to bottom are: 1. The rotational speed of the turbine and its reference 2. the power output from the unit and the calculated maximum output power 3 . the $C_{p}$-value 4 . the wind speed

ertia, would do a better job of filtering these "bumps". The effect of the gusts on the $C_{p}$-value is quite large, however the goal of the optimizing algorithm should not be to maximize the output power over these gusts, but instead to maximize the power output during a long period of time. Otherwise the control would be forced to be very aggressive and "nervous" which is not desirable.

\subsection{Active and Reactive Power Output Dur- ing Operation}

This case has been designed in order to test as many features of the Power Controller as possible. To do this the wind speed varies from $0-23 \mathrm{~m} / \mathrm{s}$ during the simulation. This should cause the power controller to shut down the wind power unit both for too high and too low wind speeds. It should also optimize the power output when the wind speed is too low for nominal power and control the power output when the wind speed is sufficient. More importantly it should also confirm that the transition between the different control modes work well. The limits for low and high wind speed were chosen to 6 respectively $20 \mathrm{~m} / \mathrm{s}$.

The simulation has been divided into 7 different zones, depicted in figure 10 and 11 .

1. The wind speed starts at $0 \mathrm{~m} / \mathrm{s}$ and increases to $5 \mathrm{~m} / \mathrm{s}$. During this period the rotor's rotational speed and the power reference are both zero, since the wind speed is too low for operation of the plant.
2. In this zone the wind speed is increased from 5 $\mathrm{m} / \mathrm{s}$ to $10 \mathrm{~m} / \mathrm{s}$ which is enough to allow operation of the unit. The power reference is raised to its nominal value, $3000 \mathrm{~W}$, and the rotor starts to rotate. Since the wind speed is not high enough for nominal power the Power Controller tries to optimize the unit's power output, as can be seen in the graph of the $C_{p}$-value in the third subplot of figure 10.

3. In this zone the wind increases further and is now high enough to allow operation at nominal effect.

4. In this zone the wind speed increases to $23 \mathrm{~m} / \mathrm{s}$, which is more than the maximum allowed for operation. Hence the power reference value is decreased to zero and the generator decelerates the rotor speed. When the rotational speed is low enough the brake is applied and the rotor stops.

5. The wind speed is now reduced to $18 \mathrm{~m} / \mathrm{s}$, which is lower than the maximum allowed wind speed for operation, and the power reference is increased to its nominal value and the rotor starts to rotate again. Since the wind speed is high enough for nominal power the Power Controller controls the power to this value.

6. The wind speed is now reduced to $11 \mathrm{~m} / \mathrm{s}$ which is too low for nominal power and the Power Controller tries to optimize the unit's output power, which can be seen on the $C_{p}$-value in the third subplot of figure 10 .

7. In this zone the wind speed is decreased to $3 \mathrm{~m} / \mathrm{s}$ which is well below the minimum allowed wind speed. This causes the Turbine Control to give orders to shut down the wind power unit. The power reference is set to zero and the generator decelerates the rotor. When the rotor's rotational speed is low enough the brake is applied.

As can be seen in zone 1, 4 and 7 the Turbine Control successfully makes the decision to turn off the unit when the wind is either too high or too low for operation. The transition between the different control modes, which can be seen going from zone 2 to 3 and 5 to $6^{3}$, is working correctly. In the transition from zone 2 and 3 a small power overshoot is present before the Power Controller manages to counteract the increased wind speed. In zone 2 and 6 it can be seen that the

\footnotetext{
3 in zone 2 to 3 the transition between optimization and nominal power can be observed, and in zone 5 to 6 the transition between nominal power and optimization can be observed.
} 


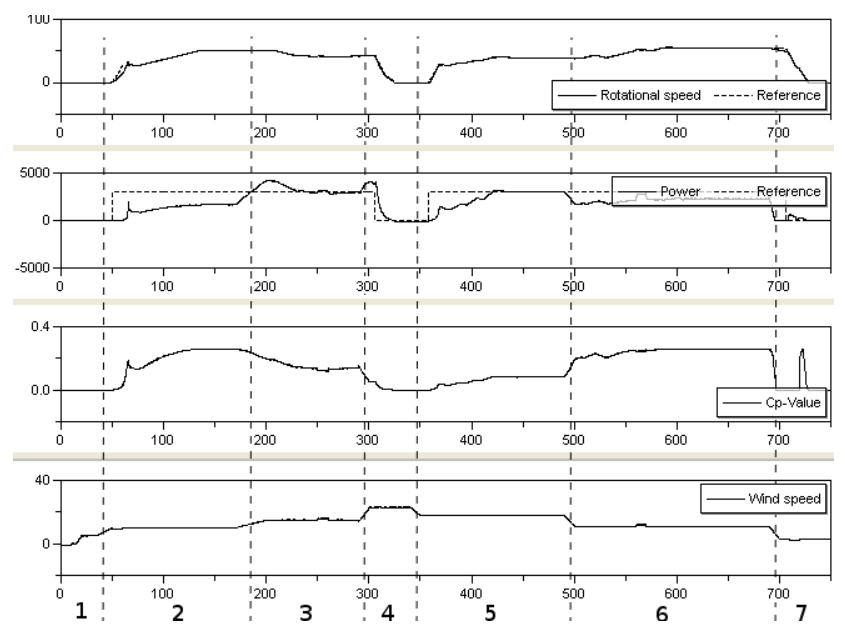

Figure 10: Simulation results, plotted for top to bottom are: 1. the rotational speed of the turbine and its reference 2. the power output from the unit and its reference 3. the $C_{p}$-value 4 . the wind speed

Power Controller successfully finds the optimal operation point. In zone 3 and 5 it can be seen that the Power Controller successfully controls the output power to its nominal value, $3 \mathrm{~kW}$. When observing the $C_{p}$-value in zone 7 a large spike can be observed. The reason for this is that when the rotor decelerates it passes through its optimal rotational speed.

In figure 11 the results from the grid side control of the plant are presented. As expected the direct voltage is high above the nominal voltage of $230 \mathrm{~V}$ during the time the reactive power compensation is inactive, and the reactive power output during the same time period is zero, according to Swedish grid codes [2]. The reactive power compensation is turned on after $350 \mathrm{~s}$, when the plant is at standstill. When the operation resumes it can be noticed that the direct voltage is controlled to its nominal value, $230 \mathrm{~V}$. Because of the reactive power flow the active power delivered to the point of connection is slightly lower than without reactive compensation.

\subsection{Island Operation}

This test case was designed to test how the plant manages to run in Island mode, that is to on its own power up and control the voltage and frequency of the ACgrid. This is done by ordering the grid connection to control the AC-voltage and frequency and the wind power unit to control the DC-voltage level.

The results from the simulation are presented in figure 12. As can be seen the power controller successfully controls the DC-level to $900 \mathrm{~V}$ with some deviations. At the start the Plant Control orders the wind

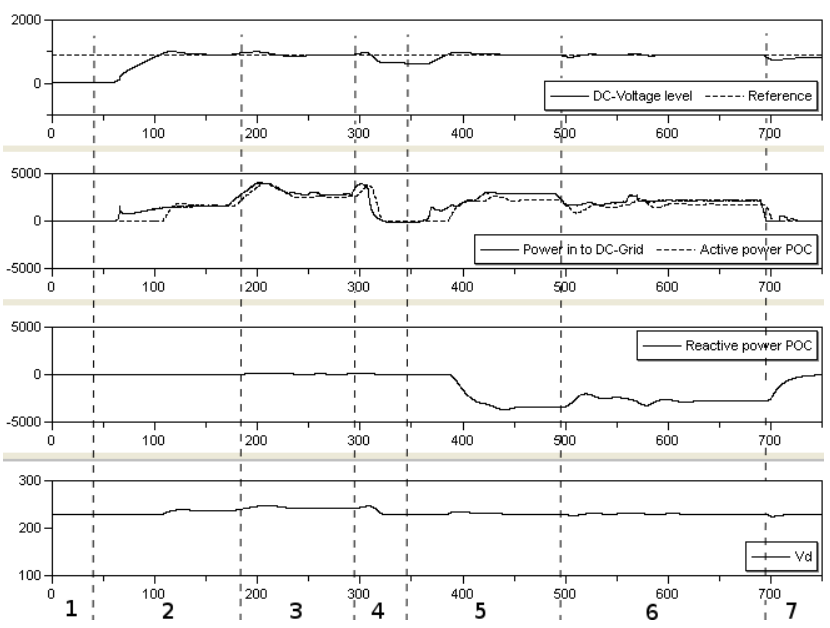

Figure 11: Simulation results, plotted from top to bottom are: 1. the DC-voltage level and its reference 2. the power flow into the DC-grid and active power flow out from the DC-grid 3. the reactive power flow out from the DC-grid 4. the direct voltage

power unit to output $1000 \mathrm{~W}$ to power up the DClink capacitor. When the DC-level reaches $850 \mathrm{~V}$ the grid controller starts powering up the grid. When the power flow from the DC-grid has started the Plant Control waits until accurate power readings have been achieved and then orders the wind power unit to control the DC-voltage level. The Power Controller manages to relatively fast control the DC-voltage to $900 \mathrm{~V}$. After 250s the load is increased which causes the DCvoltage to start decreasing. When the DC-voltage drops the power reference is changed in order to restore the DC-voltage. As depicted in figure 12 the grid controller does not have any trouble to power up the grid, and the drop in the DC-level is not so big that it has any effect on the inverter output. The effect of the load's oscillation is visible in the DC-voltage which also is experiencing a small oscillation. However this oscillation can be neglected since it has no major effect on the system. The DC-control has no apparent problems controlling the DC-level when a varying load is connected.

\section{Conclusion}

This work has shown that Modelica and Dymola are powerful tools for modeling a wind power plant including power electronics. It has also been shown that it can be used to test and evaluate control algorithms before the plant is built.

All the models and control algorithms were tested using different simulations. The different simulations 

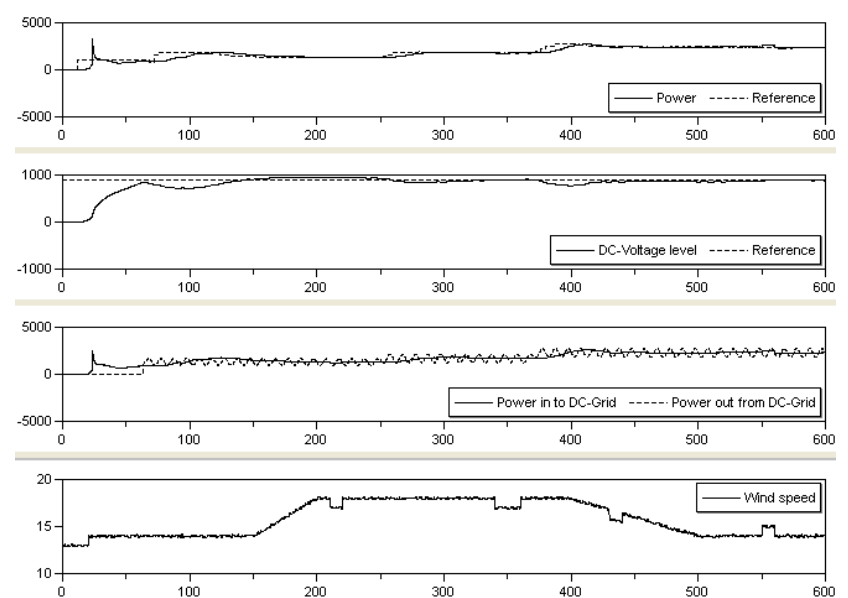

Figure 12: Simulation results, plotted from top to bottom are: 1. the power output from the wind power unit and its reference 2. the DC-voltage level and its reference 3. the power in and out from the DC-grid 4. the wind speed

tests the performance of the control algorithms during different conditions. Apart from the controls discussed some algorithms with the sole purpose of optimizing the control algorithms were also tested [6]. Unfortunately it was not possible to verify the models against real measurement data. The models are however considered to be good enough to test the control strategies. The general properties of the system are considered to be correct since the power extraction from wind power turbines is quite well documented [3][4], as well is most power electronics and generators.

During the project the performance of the control system was tested and evaluated compared to grid codes of Denmark and Sweden. Some paragraphs were not taken into account when designing the control. These grid codes would require some additional control modes, but no obvious problem in implementing that into the system was found. The details of these tests, as well as more simulation cases can be found in [6]. The performance of the control algorithms was in general good and achieved virtually all the grid codes tested.

\section{References}

[1] Energinet.dk, "Technical regulation 3.2.5 for wind power plants with a power output greater than 11 kw." Available at http://www . energinet.dk/SiteCollectionDocuments/ Engelske20dokumenter/E1/Grid20Code203. 2 .
420Power20Unit20above201120kW20and20up20to201, 520MW. pdf 2011-10-24.

[2] Svenska-Kraftnät, "Technical regulation 3.2.5 for wind power plants with a power output greater than 11 kw." Available at http://www.svk.se/Global/07_Tekniska_ $\mathrm{krav} /$ Pdf/Foreskrifter/SvKFS2005_2.pdf 2011-10-24.

[3] I. Catana, C.-A. Safta, and V. Panduru, "Power optimization control system of wind turbines by changing the pitch angle," U.P.B. Sci. Bull., Series D, Vol. 72, Iss. 1, pp. 142-146, 2010.

[4] A. Pintea, D.Popescu, and I. Pisica, "Robust model based control method for wind energy production," MCPL'2010: 5th Conference on Management and Control of Production, Coimbra : Portugal (2010), 2010.

[5] W. Hu, Y. Wang, X. Song, and Z. Wang, "Development of vertical-axis wind turbine with asynchronus generator interconnected to the electric network," Electrical Machines and Systems, 2008. ICEMS 2008. International Conference on, pp. 2289-2293, 2008.

[6] J. Petersson and P. Isaksson, "Modeling and simulation of a vertical wind power plant in dymola/modelica." Master's thesis, Department of Industrial Electrical Engineering and Automation, Lund University, 2011, http:// Www.iea.lth.se/publications/MS-Theses/ Full\%20document/5290_full_document.pdf.

[7] J. Thongham, P. Bouchard, H. Ezzaidi, and M. Ouhrouche, "Wind speed sensorless maximum power point tracking control of variable speed wind energy conversion systems," Electric Machines and Drives Conference, 2009. IEMDC '09. IEEE International, pp. 1832-1837, 2009.

[8] M. Alaküla and P. Karlsson, Power Electronics, Devices, Converters, Control and Applications. Department of Industrial Electrical Enginering and Automation, Lund Institute of Technology, 2010.

[9] Modelica-Association, "Modelica $($ - a unified object-oriented language for physical systems modeling." Available at https://www .modelica.org/documents/ ModelicaSpec32.pdf 2011-08-23. 